\title{
Magnetic Force Simulation of Cables in Microgrid during Faults
}

\author{
Bin Sun \\ Hitachi ABB Power Grids, Raleigh, USA \\ Email: bins@clemson.edu
}

How to cite this paper: Sun, B. (2020) Magnetic Force Simulation of Cables in Microgrid during Faults. Journal of Power and Energy Engineering, 8, 1-12. https://doi.org/10.4236/jpee.2020.812001

Received: October 6, 2020

Accepted: December 18, 2020

Published: December 21, 2020

Copyright $\odot 2020$ by author(s) and Scientific Research Publishing Inc. This work is licensed under the Creative Commons Attribution International License (CC BY 4.0).

http://creativecommons.org/licenses/by/4.0/ (c) (i) Open Access

\begin{abstract}
In recent years, more and more electric utilities are using underground cables to distribute electric power rather than overhead transmission line. However, the cost of installation and maintenance of underground cables is very expensive. Thus, the proper design and damage prediction of cables are crucial. This paper is focused on the magnetic force waveforms simulation of cables under different types of faults using PSCAD and COMSOL. The results show that three-phase fault leads to the largest magnetic forces and the maximum magnitude of the forces in the $\mathrm{x}$-direction is about $2.5 \mathrm{~N}$. Also, the magnetic fields surrounding the cables are different depending on the arrangements of cables buried method. Although the magnitude is small, considering the long distance and long operating time of underground cables, the forces between cables can cause failures under some conditions. In the future, more types of faults such as high impedance fault and different protecting technologies can be studied.
\end{abstract}

\section{Keywords}

Microgrid Simulation, Magnetic Force Simulation, Fault, Cable, PSCAD, COMSOL

\section{Introduction}

Underground cables provide more convenience than overhead transmission lines since they are deeply buried underground. With the development of related technology, cables are used more and more frequently in power system. To predict the damage of switching and different faults on cables, it is important to simulate and analyze the magnetic forces of cables under different system conditions.

Several published papers have studied underground cables [1]-[6], but they 
are focused on the steady-state analysis. Few papers are focused on the magnetic field simulation [7] [8] [9]. But no paper is simulating the magnetic forces during capacitor switching and different types of faults. So the objective of this paper is to simulate and analyze the forces waveforms of cables during different situations such as capacitor switching and faults. The current data of cables during capacitor switching and different types of faults are achieved using PSCAD; and the related magnetic forces on cables are calculated and simulated using COMSOL.

\section{Methods}

There are three steps to simulate the magnetic force of cables in a microgrid: firstly, using POWERWORLD software to design the microgrid based on an existing published paper [10]; secondly, building the system in PSCAD to obtain current data under capacitor switching and faults; thirdly, calculating and simulating the force waveform using Maxwell equations by COMSOL. The roadmap is shown in Figure 1.

\subsection{Microgrid Design and Simulation}

To collect the three-phase currents data of the underground cable in a microgrid system, a microgrid includes synchronous machine, PV and nonlinear loads was designed using POWERWORLD and simulated in PSCAD. The loads and generators data of the microgrid is based on the paper [10]. The overhead transmission lines and underground cables sizes are selected using POWERWROLD and it is showed in Figure 2. The microgrid simulated in PSCAD is showed in Figure 3.

In this system, Bus 1 to Bus 2 and Bus 2 to Bus 3 use overhead transmission lines and all others use underground cables. These cables are single conductor cables with direct burial method, which is shown in Figure 4. Using this microgrid, capacitor switching, and different types of faults can be introduced, and the currents waveform in different lines under different transient conditions can be obtained if needed.

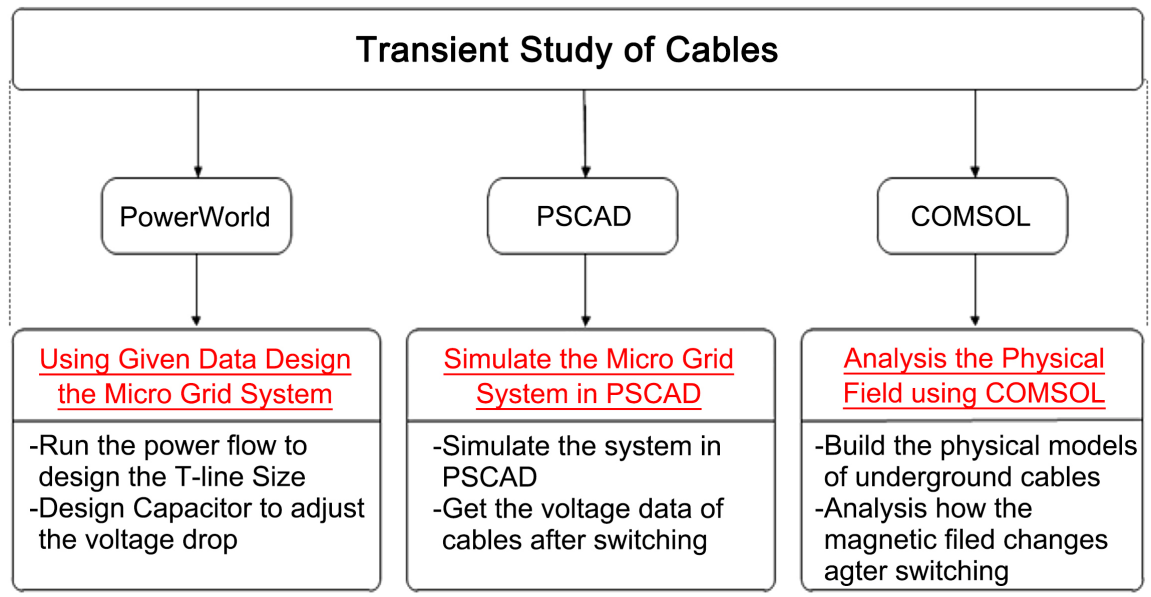

Figure 1. The roadmap of magnetic force simulation of cables in microgrid. 


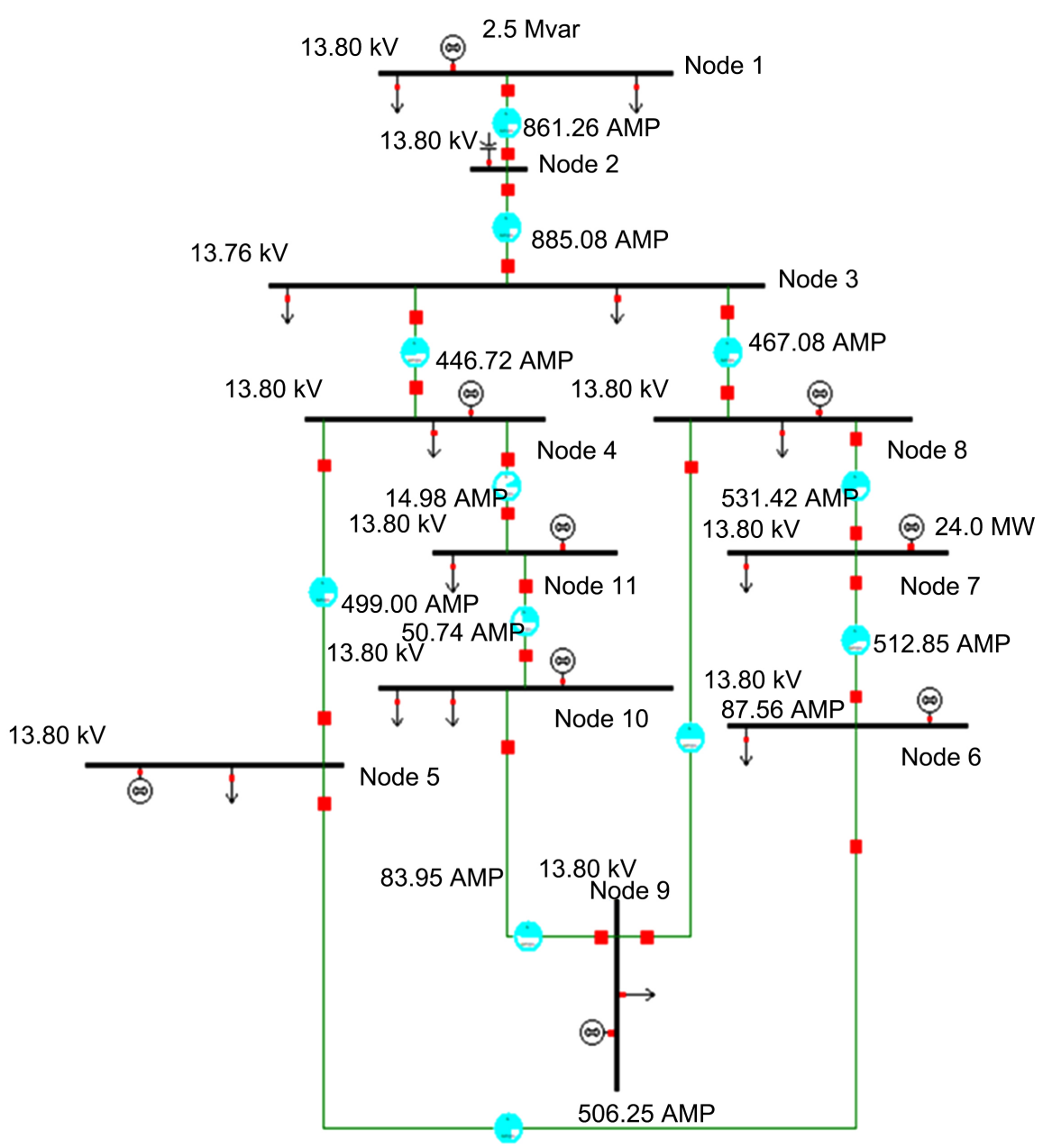

Figure 2. Power flow results of POWERWORLD software.

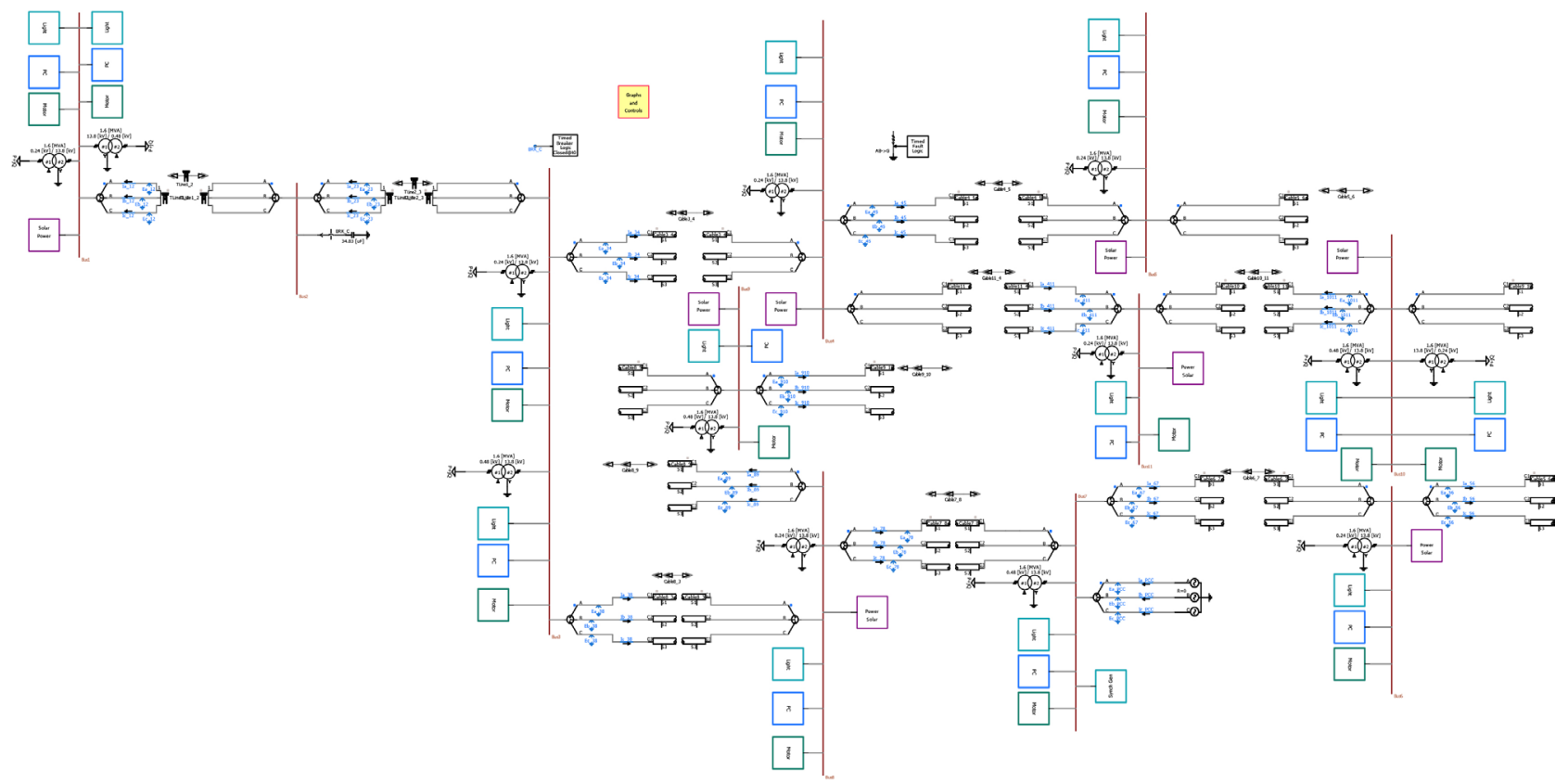

Figure 3. Microgrid system used to collect current data. 


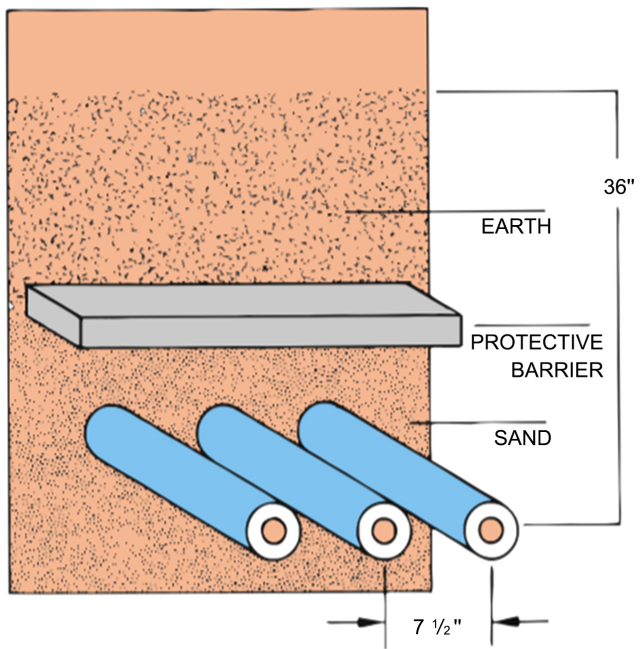

\section{Single \\ conductor cable \\ direct burical}

$1 / \mathrm{C}$ group buried 36" deep with cables laid on 7-1/2" centers, open circuited shield operation, i.e. shields bonded and grounded at one point only. Earth ambient temperature $20^{\circ} \mathrm{C}$ Earth thermal resistivity $\mathrm{RHO} 90$ $100 \%$ load factor

Figure 4. Arrangement of direct burial shield cables [11].

After the parameters of cables, generators and loads are calculated, the microgrid system is built in PSCAD. Three main parts form this system. Firstly, the cables and T-lines model should be established in PSCAD using pi model or frequency dependent model. Secondly, the PV arrays should be designed to match the DGs data. Thirdly, a steam turbine, including exciter, governor and turbine model, should be built as main source for the selected microgrid system.

The PV array test system is shown in Figure 5 and the PV model includes PV array, Maximum Power Point Tracker System, DC converter, inverter, and the transformer, as shown in Figure 6. The PV models are modified based on several publications [12] [13] [14]. The output signals of PV array are filtered by a low pass filter, which is basically an RC circuit, to filter out the high-frequency noise in these signals. Then after filtering, these signals are the inputs of the maximum power point tracker system. It is widely known that when PV array operates under different voltage, the maximum power output of this PV array is different. Thus, the best operating voltage can be calculated. Then the DC-DC converter is used to force the PV array to operate under the best operating voltage. The DC-DC converter includes a PWM circuit, insulated-gate bipolar transistor (IGBT), diode, capacitor, and inductor. The signal of the IGBT gate is generated by the PWM circuit, and this signal can force IGBT to switch on and off. This continuous switching on and off forces the inductor and capacitor to continue charging and discharging and eventually keeps the PV array operating under the best voltage condition. Then the converter is connected with a DC-AC inverter, which includes the PQ circuit and three-phase bridge circuit. The PQ circuit generates three sine-waves and, compared with a triangular wave, generates the signals of this bridge circuit. The six IGBTs of the bridge circuit convert DC voltage of the PV array to AC voltage that can be connected with the main AC power system. When all distributed generations are finished, the main steam turbine source can be connected to the system, which is shown in Figure 7. The model for this steam turbine source is built based on the synchronous machine 
study [15]. But since the hydro turbine has several restrictions based on the season and water level, it needs to be replaced by a steam turbine and a similar method to initialize and control it should be used. Finally, the three main parts of the entire microgrid system are connected together using different sizes of T-Lines and cables to form the microgrid system to be studied, which is shown in Figure 3. To mitigate the voltage drop at Bus 2, a large capacitor is added at this bus. If the capacitor is switched off, it can be seen how this transient passes through the microgrid system and the voltage and current data of cables after switching can be obtained at the cable terminals, which can be used as the input in COMSOL to simulate and analyze the magnetic force after switching and faults.

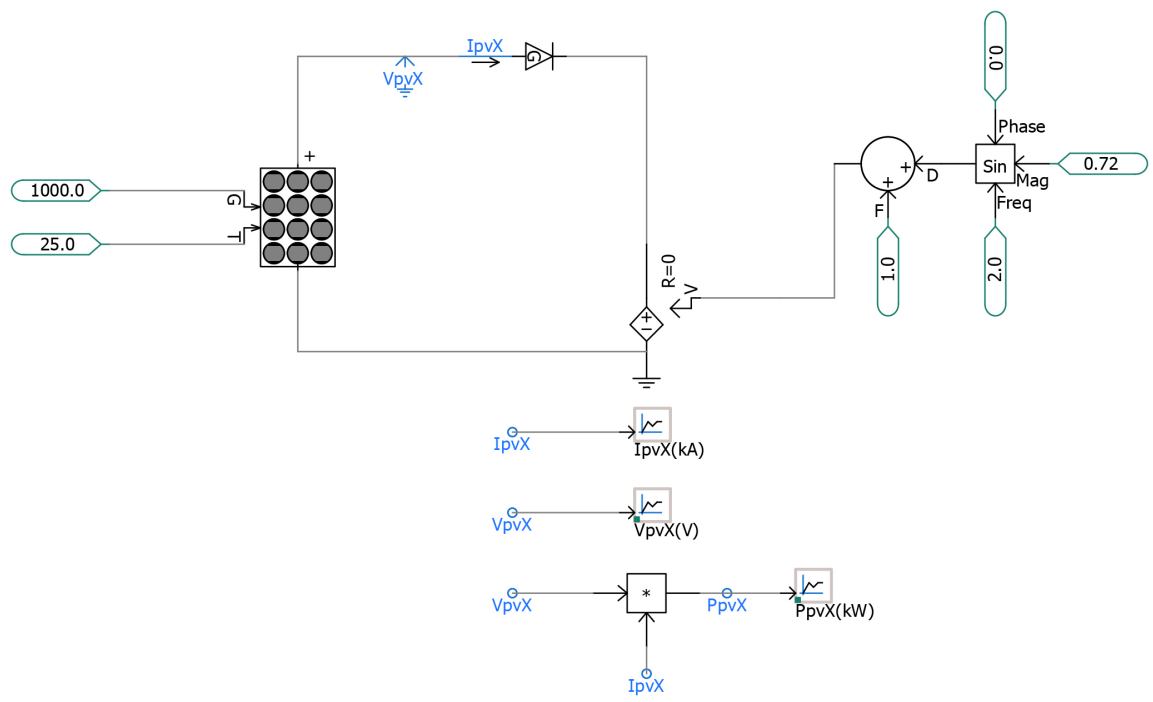

Figure 5. PV array testing system.
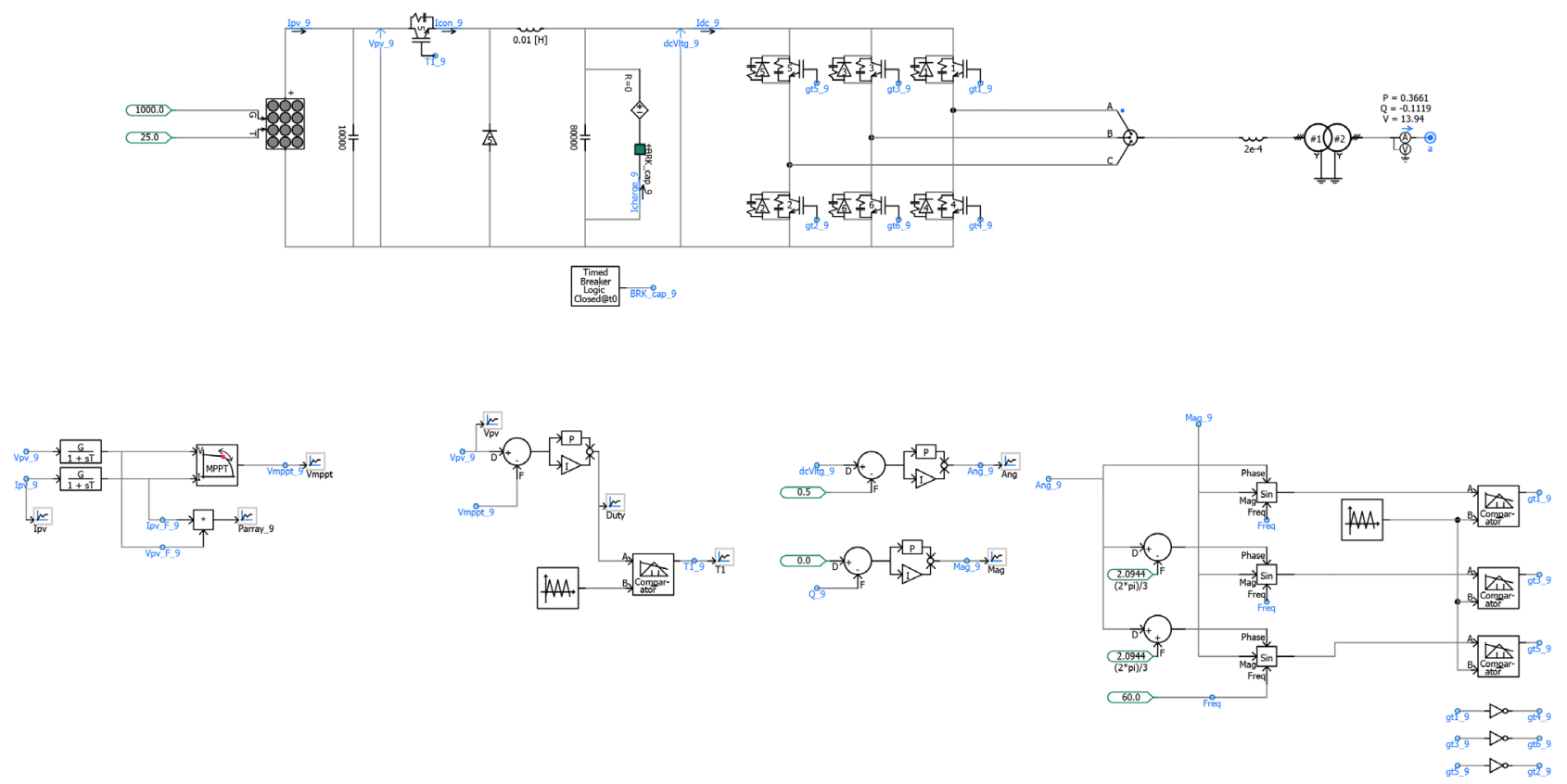

Figure 6. PV model includes MPPT, converter, inverter, and transformer. 


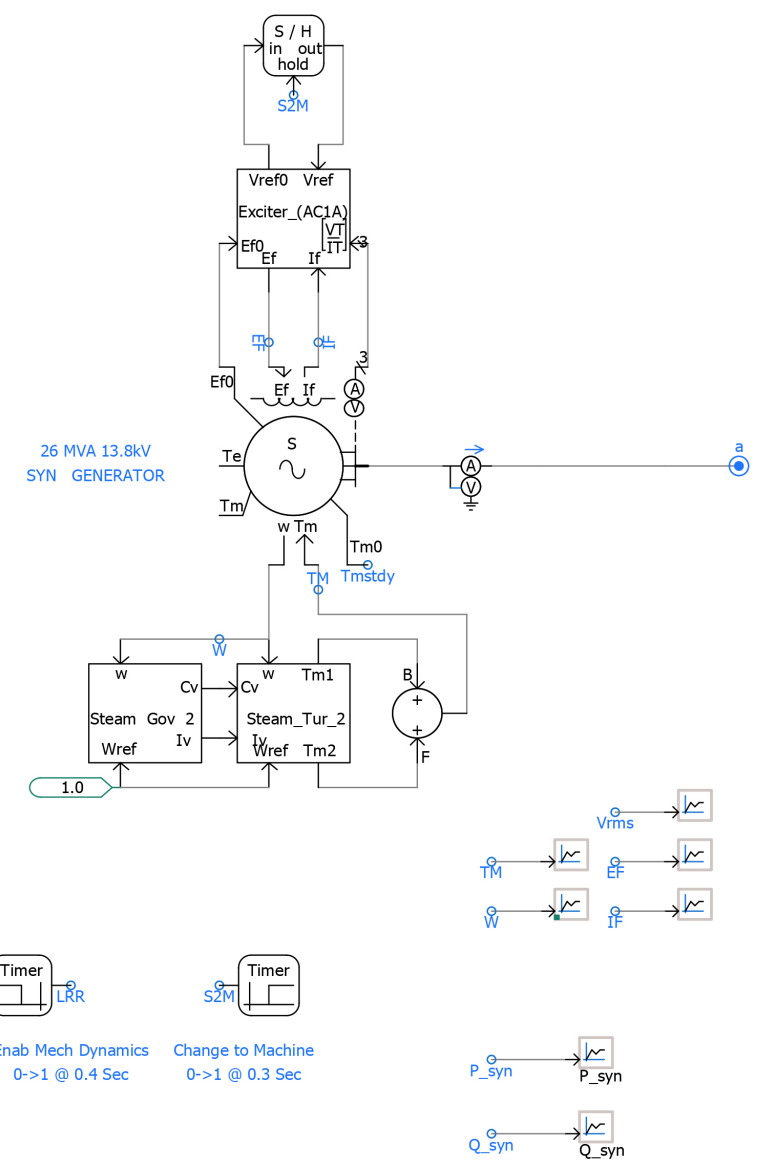

Figure 7. Steam turbine synchronous machine.

\subsection{Cable Model in COMSOL}

The magnetic force calculation was completed using COMSOL. Using this multi-physics modeling software, physical models for three-phase insulated underground power cables were built. The current transient waveforms due to capacitor switching and faults of the three-phase cable from Bus 3 to Bus 4 in Figure 3 under different conditions were exported from PSCAD to COMSOL. The curve of force as a function of time was calculated and plotted using Maxwell's equations in COMSOL.

$$
\begin{gathered}
\nabla \times H=J+\frac{\partial D}{\partial t} \\
\nabla \times E=-\frac{\partial B}{\partial t} \\
\nabla \cdot D=\rho \\
\nabla \cdot B=0 \\
D=\varepsilon E \quad B=\mu H
\end{gathered}
$$

where $\nabla \times$ is the curl operator; $\nabla$. is the divergence operator; $J$ is the electric current density; $\mathrm{D}$ is the electric flux density; $\rho$ is the electric charge density; $B$ is the magnetic flux density; $H$ is the magnetic field; $E$ is the electric field; $\varepsilon$ is the permittivity; $\mu$ is the permeability. 


\section{Results}

Using the microgrid in Figure 3, capacitor switching and different types of faults can be introduced to the system. Then the current data of the three-phase cable from Bus 3 to Bus 4 were exported from PSCAD to COMSOL to simulate and analyze the magnetic force after faults. The curve of force as a function of time was calculated and plotted using Maxwell's equations in COMSOL. The faults are introduced into the system at 1.5 second and cleared after 0.05 second. The arrangement of cables is shown in Figure 4.

When the capacitor of Bus 2 is switched, the results of currents waveforms of different phases and force are shown in Figure 8.

When the single-line-to-ground fault (SLGF) occurs on cables from Bus 3 to Bus 4 , the results of currents waveforms of different phases and force are shown in Figure 9.

When the line-to-line fault (LLF) occurs on cables from Bus 3 to Bus 4, the results of currents waveforms of different phases and force are shown in Figure 10.

When the double-line-ground fault (2LGF) occurs on cables from Bus 3 to Bus 4, the results of currents waveforms of different phases and force are shown in Figure 11.

When a three-phase fault (3PF) occurs on cables from Bus 3 to Bus 4, the fault currents from the three phases and the force results are shown in Figure 12.

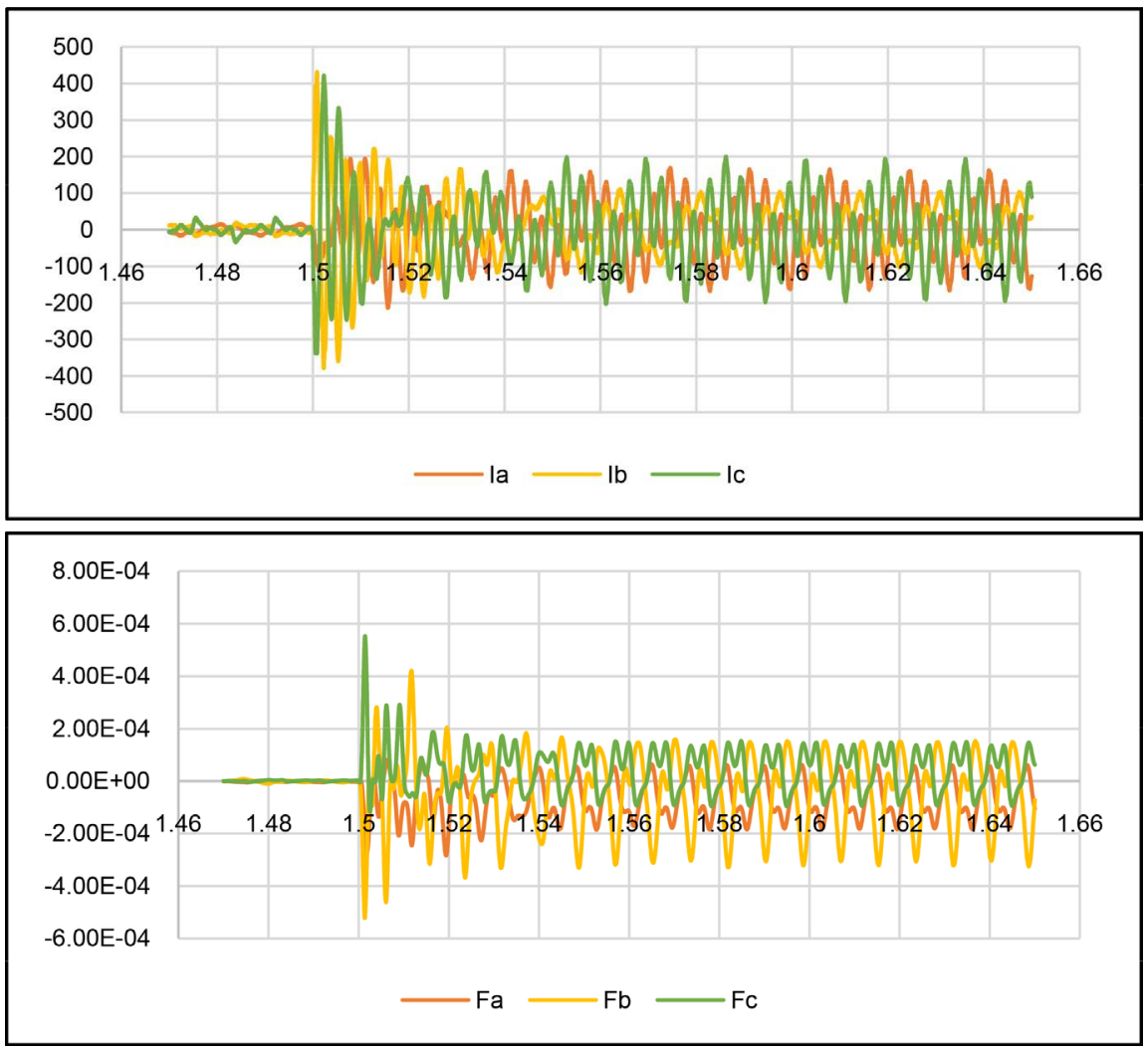

Figure 8. Forces of cables in the $\mathrm{x}$-direction after capacitor switching. 

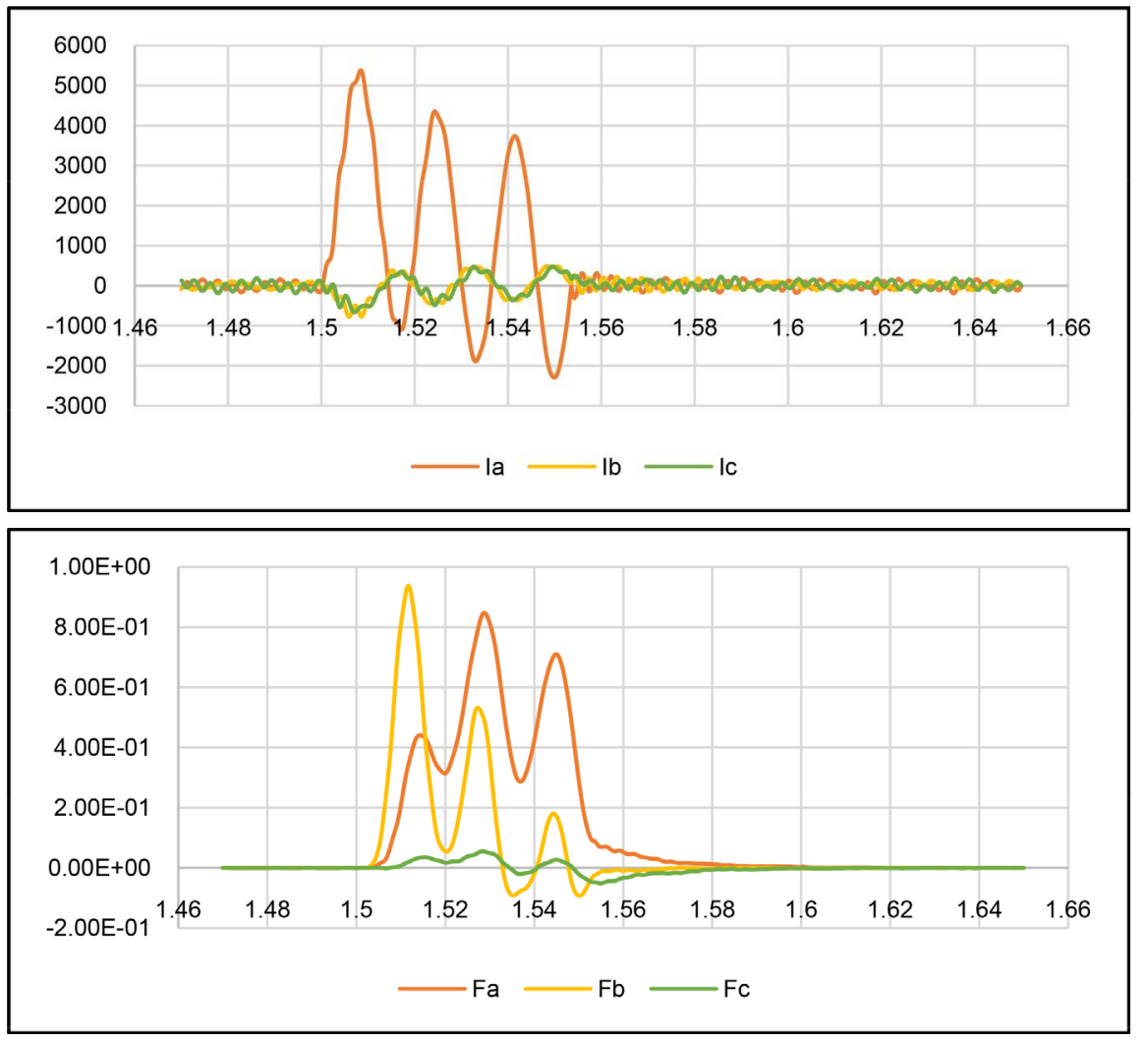

Figure 9. Forces of cables in the x-direction after SLGF.
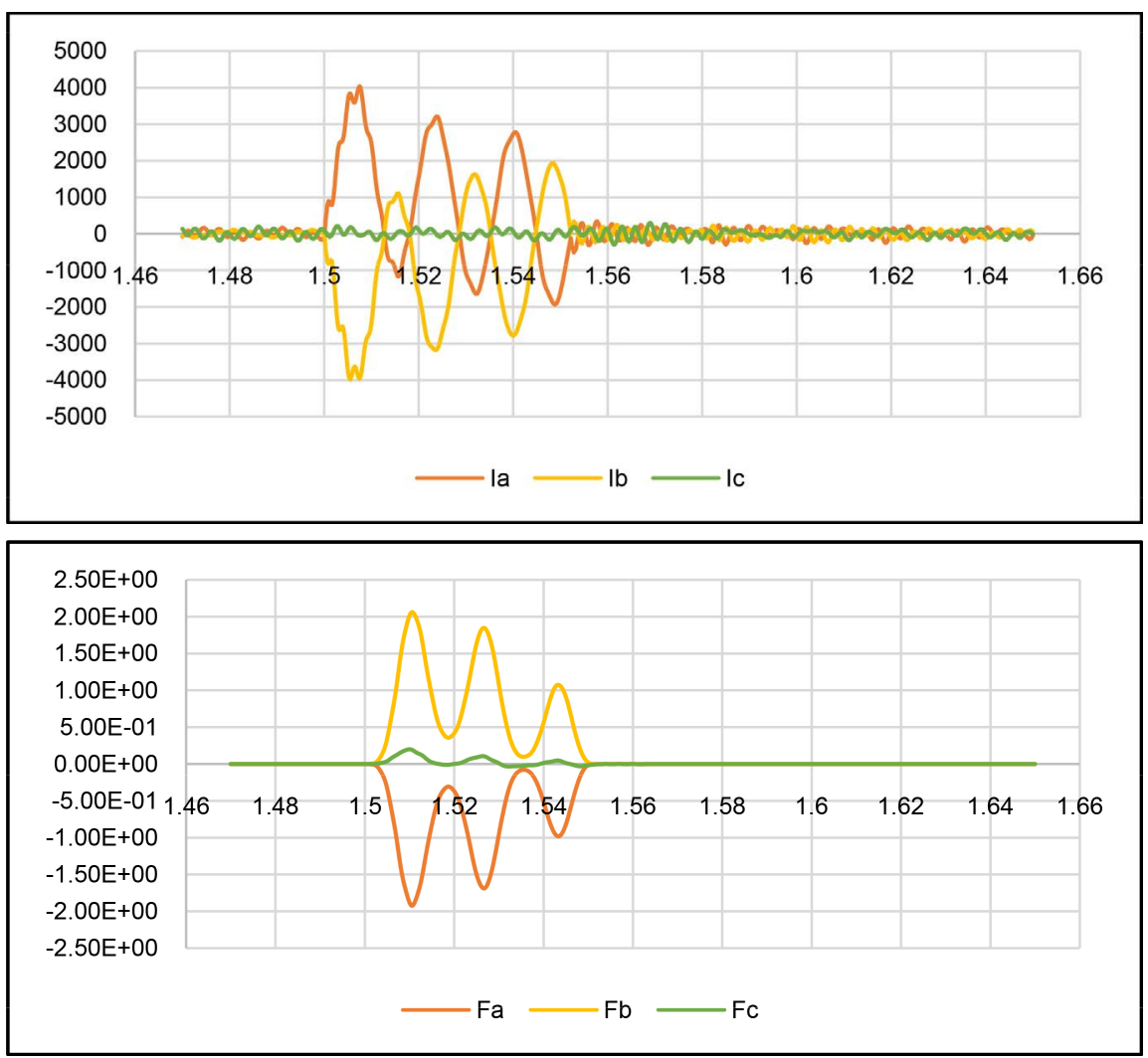

Figure 10. Forces of cables in the x-direction after LLF. 

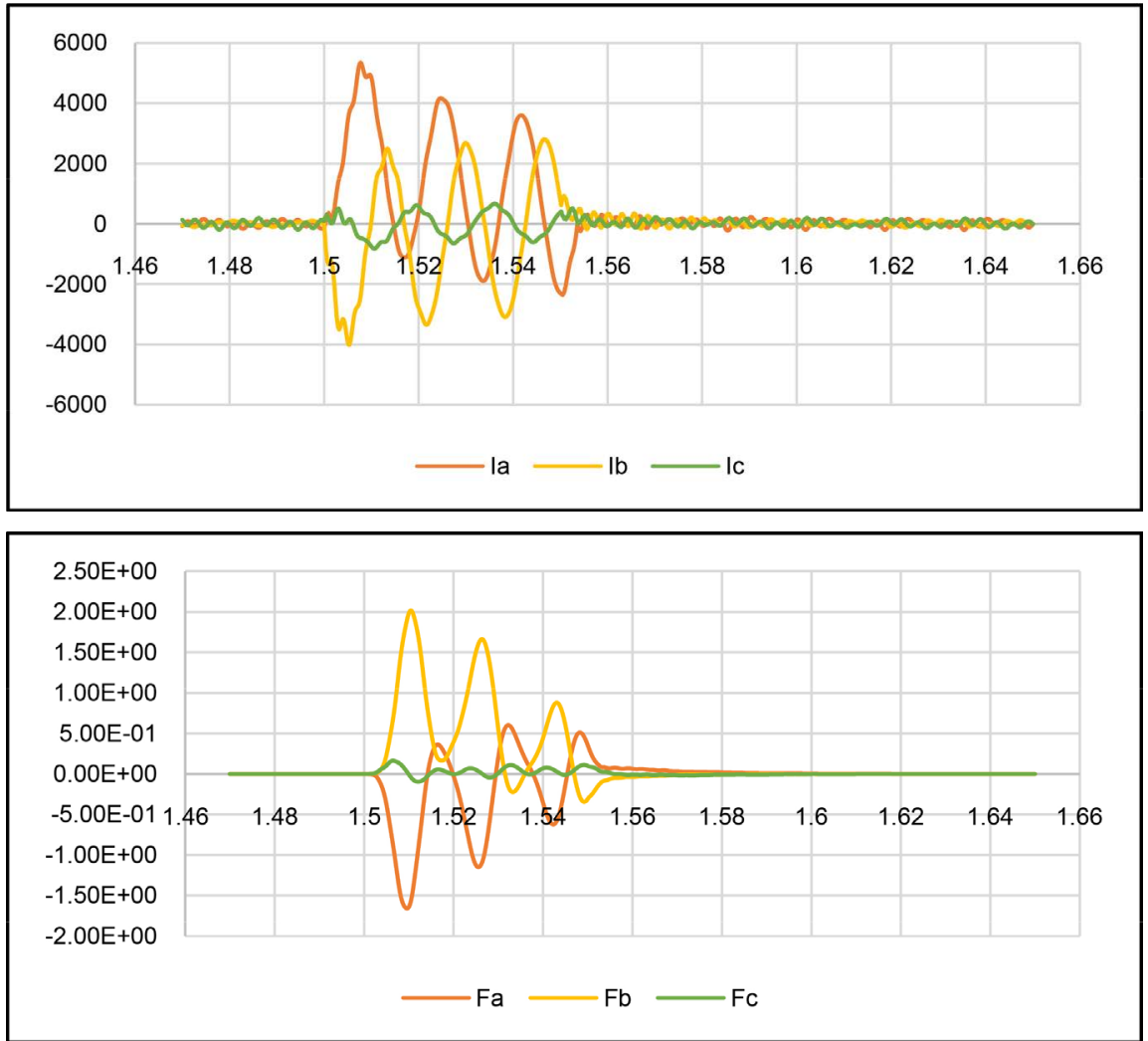

Figure 11. Forces of cables in the x-direction after 2LGF.
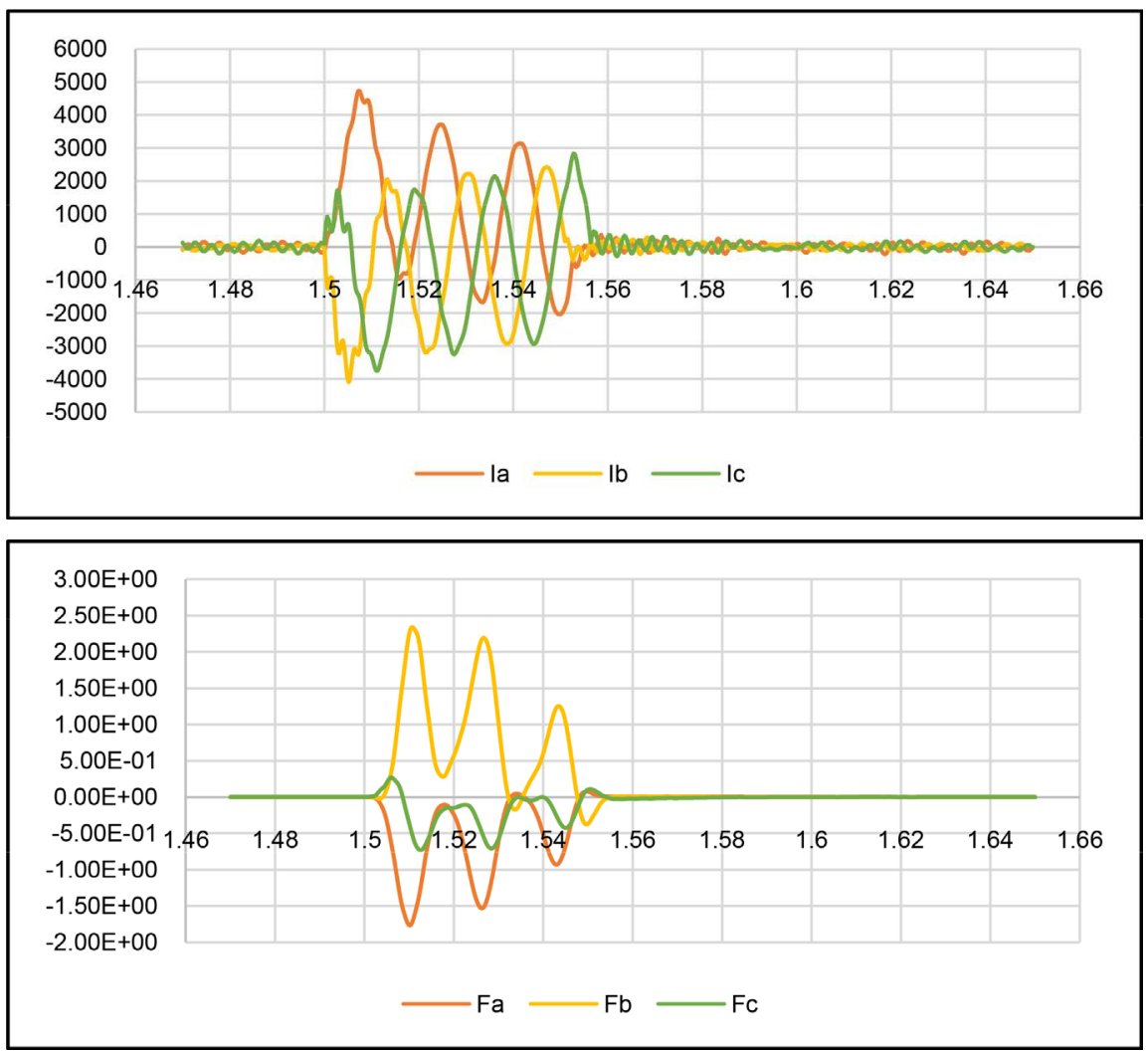

Figure 12. Forces of cables in the $\mathrm{x}$-direction after $3 \mathrm{PF}$. 
Figure 8 shows that the large capacitor at bus 2 is switched at 1.5 second and the currents reach the peak values immediately and then decrease. Since this microgrid system is unbalanced, the phase A peak current value is $200 \mathrm{~A}$ and decreases to $170 \mathrm{~A}$ after 0.02 seconds. The phase $\mathrm{B}$ peak current value is $420 \mathrm{~A}$ and declines to $110 \mathrm{~A}$. The phase $\mathrm{C}$ peak current value is $420 \mathrm{~A}$ and reduces to $200 \mathrm{~A}$. The magnetic forces are showing a similar pattern. The magnetic forces reach the peak values immediately and decrease. The phase A peak force value is $3 \mathrm{e}-4$ $\mathrm{N}$ and reduces to $1.85 \mathrm{e}-4 \mathrm{~N}$ after 0.02 seconds. The phase $\mathrm{B}$ peak force value is about $5.2 \mathrm{e}-4 \mathrm{~N}$ and declines to $3.3 \mathrm{e}-4 \mathrm{~N}$. The phase $\mathrm{C}$ peak force value is $5.5 \mathrm{e}-4$ $\mathrm{N}$ and decreases to $1.5 \mathrm{e}-4 \mathrm{~N}$. Figure 9 shows that the SLGF occurs at 1.5 second and is cleared after 0.05 seconds. The phase A peak current value is $5300 \mathrm{~A}$ and decreases to $240 \mathrm{~A}$ after the fault is cleared. The phase $\mathrm{B}$ peak value is $780 \mathrm{~A}$ and reduces to $240 \mathrm{~A}$. The phase $\mathrm{C}$ peak current value is $670 \mathrm{~A}$ and declines to $240 \mathrm{~A}$. The peak forces value of phase A cable reach is $0.85 \mathrm{~N}$ and decreases to almost zero gradually at 1.6 second. The peak forces value of phase $\mathrm{B}$ cable is about 0.94 $\mathrm{N}$ and reduces gradually. The peak force value of phase $\mathrm{C}$ cable is $0.055 \mathrm{~N}$ and declines to ignorable gradually. Figure 10 shows that the LLF occurs at 1.5 second and is cleared after 0.05 seconds. The fault current and forces of phase A and phase $\mathrm{B}$ have the same magnitude but opposite direction, and they decrease gradually after the fault occurs. The peak current value is $4000 \mathrm{~A}$ at 1.507 second and it decreases to $300 \mathrm{~A}$ at 1.55 second. The magnetic forces are showing a similar pattern. The forces of phase A cable and phase B cable reach their peak values of $2 \mathrm{~N}$ at 1.51 second and decrease gradually to ignorable after the fault is cleared. Figure 11 shows that the 2LGF occurs at 1.5 second and is cleared after 0.05 seconds. The phase A peak current value is about $5000 \mathrm{~A}$ at 1.508 second and decreases to $260 \mathrm{~A}$ after the fault is cleared. The phase $\mathrm{B}$ peak current value is about $2800 \mathrm{~A}$ and declines to $350 \mathrm{~A}$. The phase $\mathrm{C}$ peak current value is about $825 \mathrm{~A}$ and reduces to $200 \mathrm{~A}$. The phase $\mathrm{A}$ and phase $\mathrm{B}$ magnetic forces are showing similar patterns but with different directions. The magnetic forces reach the peak values and decrease gradually. The phase A peak force value is $1.66 \mathrm{~N}$ at 1.51 second and decreases gradually to ignorable at 1.58 second. The phase $\mathrm{B}$ peak force value is $2 \mathrm{~N}$ and decreases gradually to ignorable. The phase $\mathrm{C}$ peak force value is $0.16 \mathrm{~N}$ and decreases gradually to almost zero at 1.58 second. Figure 12 shows that the $3 \mathrm{PF}$ occurs at 1.5 second and is cleared after 0.05 seconds. The phase A peak current value is about $4750 \mathrm{~A}$ at 1.507 second and decreases to $275 \mathrm{~A}$ after the fault is cleared. The phase B peak current value is about $4000 \mathrm{~A}$ and declines to $300 \mathrm{~A}$. The phase $\mathrm{C}$ peak current value is about $3750 \mathrm{~A}$ and decreases to $360 \mathrm{~A}$ after the fault is cleared. The magnetic forces reach the peak values and decrease gradually. The phase A peak force value is $1.77 \mathrm{~N}$ at 1.51 second and gradually decreases to ignorable at 1.555 second. The phase B peak force value is $2.3 \mathrm{~N}$ and decrease gradually to ignorable. The phase $\mathrm{C}$ peak force value is $0.7 \mathrm{~N}$ and decreases gradually to almost zero.

Comparing these figures together shows that the SLGF leads to the smallest 
magnetic forces, which is about $0.95 \mathrm{~N}$ and the three-phase fault leads to the largest magnetic forces and the maximum magnitude of the forces in the $\mathrm{x}$-direction is about $2.5 \mathrm{~N}$. Also, it shows that the LLF and 2LGF have similar force waveform and the peak values are both about $2 \mathrm{~N}$. The results are based on the arrangements of cables buried method, which is shown in Figure 4. Even though the magnitude is small, considering the long distance and long operating time of underground cables, the forces can cause failure of cables under some conditions. So the utilities need to design proper holders or duct banks based on the length of cables to fix the cables. In the future, more three-dimension models can be studied, and different cable burial methods can be compared using the similar method.

\section{Conclusion}

Underground cables offer more advantages than overhead lines since cables are better protected and do not detract from the appearance of urban areas. In recent years, more and more electrical utilities are using cables to distribute electric power to their customers. However, the cost of installation and maintenance of underground cables is very expensive. Thus, the proper design and damage prediction of cables are crucial. Based on this study, the magnetic force waveforms of cables under different types of faults are plotted using PSCAD and COMSOL. The magnitudes of magnetic forces are investigated and compared under different types of faults. The results show that three-phase fault leads to the largest magnetic forces and the maximum magnitude of the forces in the $\mathrm{x}$-direction is about $2.5 \mathrm{~N}$. Also, the magnetic fields surrounding the cables are different depending on the arrangements of cables buried method. Even though the magnitude is small, considering the long distance and long operating time of underground cables, the forces can cause failure of cables under some conditions. So the utilities need to design proper holders and duct banks based on the length of cables to fix the cables even under the worst condition.

\section{Conflicts of Interest}

The author declares no conflicts of interest regarding the publication of this paper.

\section{References}

[1] Binns, D.F. (1969) Calculation of Steady-State Temperature Rise of Water-Cooled Buried Cables Using a New Iterative Method. Proceedings of the Institution of Electrical Engineering, 116, 101. https://doi.org/10.1049/piee.1969.0018

[2] Biçen, Y. and Aras, F. (2017) Steady State Effects of Design Properties and Environmental Conditions on Underground Power Cable Ampacity. 2017 10th International Conference on Electrical and Electronics Engineering, 81-84.

[3] Baù, M., Viafora, N., Hansen, C.S., Dall, L.B., Badulescu, N. and da Silva, F.M.F. (2016) Steady State Modelling of Three-Core Wire Armoured Submarine Cables. 201651 st International Universities Power Engineering Conference (UPEC), Coim- 
bra, 6-9 September 2016.

[4] Liang, Y. (2012) Steady-State Thermal Analysis of Power Cable Systems in Ducts Using Streamline-Upwind/Petrov-Galerkin Finite Element Method. IEEE Transactions on Dielectrics and Electrical Insulation, 19, 283-290, https://doi.org/10.1109/TDEI.2012.6148529

[5] Sun, B. (2020) Parameters Calculation of Underground Cables Using MATLAB. Journal of Power and Energy Engineering, 8, 12-20. https://doi.org/10.4236/jpee.2020.811002

[6] Sun, B. and Makram, E. (2018) Configuration Optimization of Cables in Ductbank Based on Their Ampacity. Journal of Power and Energy Engineering, 6, 1-15. https://doi.org/10.4236/jpee.2018.64001

[7] Xiong, Z., Fang, J. and Zhang, B. (2018) Simulation and Analysis of Magnetic Field in HVDC Transmission Cable. IOP Conference Series: Materials Science and Engineering, 382 https://doi.org/10.1088/1757-899X/382/3/032041

[8] Djekidel, R., Mahi, D., Bessedik, S.-A. and Hadjaj, C. (2016) Analysis of Magnetic Flux Density Generated by a Three-Phase Underground Power Cable. 2016 10th National Conference on High Voltage, Algiers.

[9] Sun, B., Makram, E. and Xu, X.F. (2017) Impacts of Water-Tree Fault on Ferroresonance in Underground Cables. Journal of Power and Energy Engineering, 5, 75-86. https://doi.org/10.4236/jpee.2017.512010

[10] Rudion, K., Orths, A., Styczynski, Z.A. and Strunz, K. (2006) Design of Benchmark of Medium Voltage Distribution Network for Investigation of DG Integration. 2006 IEEE Power Engineering Society General Meeting, Montreal, 18-22 June 2006, 1-6. https://doi.org/10.1109/PES.2006.1709447

[11] The Okonite Company. https://www.okonite.com/

[12] AbdelHady, R. (2017) Modeling and Simulation of a Micro Grid-Connected Solar PV System. Water Science, 31, 1-10. https://doi.org/10.1016/j.wsj.2017.04.001

[13] Rajapakse, A.D. and Muthumuni, D. (2009) Simulation Tools for Photovoltaic System Grid Integration Studies. 2009 IEEE Electrical Power \& Energy Conference (EPEC), Montreal, 22-23 October 2009, 1-5. https://doi.org/10.1109/EPEC.2009.5420370

[14] Kalbat, A. (2013) PSCAD Simulation of Grid-Tied Photovoltaic Systems and Total Harmonic Distortion analysis. 2013 3rd International Conference on Electric Power and Energy Conversion Systems, Istanbul, 2-4 October 2013, 1-5. https://doi.org/10.1109/EPECS.2013.6713002

[15] PSCAD Company. Synchronous Machine Study. 